16 a 18 de outubro de 2019 - Campinas | Brasil

\title{
Análise exergética do sistema respiratório em fumantes passivos asmáticos
}

\section{Marina T. Reis*, Carlos E. K. Mady.}

\section{Resumo}

Investigando duas questões de saúde públicas representativas atuais (a asma e o tabagismo/presença de $\mathrm{CO} 2$ no ambiente), a pesquisa busca avaliar a destruição de exergia e geração de entropia associada aos efeitos da asma isolados e ao aumento de CO2 no ambiente. Destaca-se que a presença de poluentes é um dos gatilhos da asma, contribuindo para que o quadro do paciente piore mais rapidamente. Foi utilizado um modelo computacional do sistema térmico e respiratório humano.

\section{Palavras-chave:}

Asma, dióxido de carbono, termodinâmica, exergia, entropia.

\section{Introdução}

A asma é uma doença respiratória obstrutiva caracterizada pela hipersensibilidade das vias aéreas a certos estímulos e pelo seu remodelamento, causando aumento na vascularização (principalmente pequenos vasos) e na espessura das vias aéreas (principalmente menores). Afetando, portanto, a transferência de calor e massa no sistema respiratório.

Por sua vez, o fumo passivo contribui para o aumento da pressão parcial de dióxido de carbono no sangue.

Foi utilizado um modelo computacional proposto por Albuquerque-Neto (2010) para avaliar o comportamento do sistema térmico e respiratório humano mediante alterações que buscam representar a patologia.

\section{Resultados e Discussão}

Figura 1. Geração de entropia associada à difusão.

Geração de entropia associada à transferência de gases $8,00 \mathrm{E}-06$

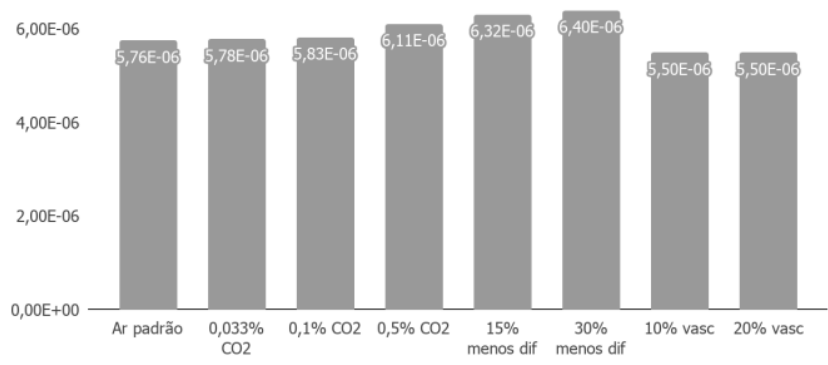

Figura 2. Débito cardíaco obtido.

Débito cardíaco
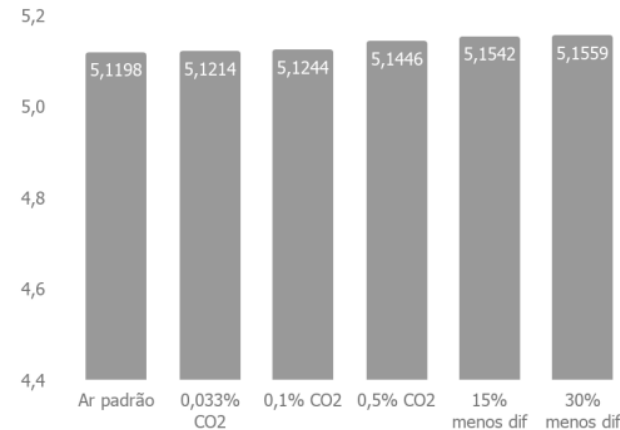

Figura 3. Ventilação pulmonar obtida. Ventilação pulmonar

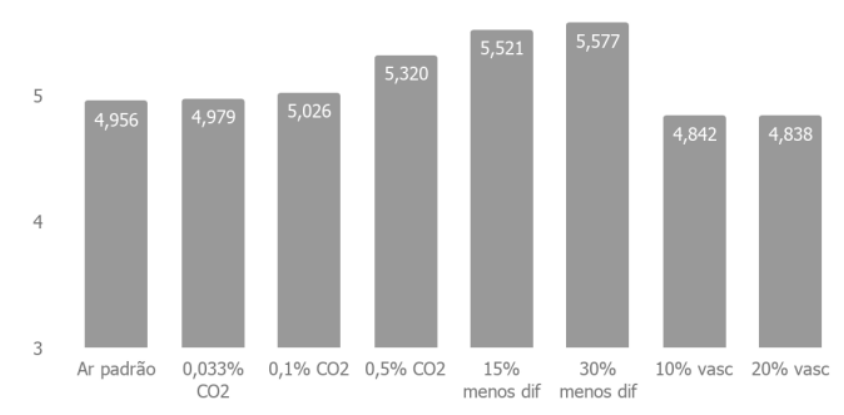

\section{Conclusões}

Esperava-se como resposta à asma: maior débito cardíaco, maior trabalho respiratório, maior vazão sanguínea nos pulmões, redução da saturação de 02 no sangue arterial, aumento da frequência respiratória, redução no volume corrente, etc.

Espera-se como resposta ao fumo passivo: aumento na ventilação e no trabalho respiratório, alterações nas pressões parciais dos gases no sangue.

Não foi possível obter completamente a resposta esperada para a asma, pois a saturação de $\mathrm{O} 2$ no sangue não diminuiu. Atribui-se esse resultado à ativação de mecanismos compensatórios, como o aumento do débito cardíaco e da frequência respiratória, que, na resposta do modelo, acabaram por superar os efeitos da redução no coeficiente de difusão dos gases.

Já para o aumento no $\mathrm{CO} 2$ ambiente, os resultados atingidos estão condizentes com o esperado.

\section{Agradecimentos}

A Cyro Albuquerque Neto, pelo modelo computacional utilizado.

Albuquerque Neto, C. - Modelo integrado dos sistemas térmico e respiratório do corpo humano - Escola Politécnica da Universidade de São Paulo, 2010.

Cenzi, J. - Efeito da intoxicação por monóxido de carbono no comportamento exergético do corpo humano - Faculdade de Engenharia Mecânica da Universidade Estadual de Campinas, 2018. 